\title{
What's new in the stomach? A report on the World Congress of Gastroenterology
}

\author{
NiCHOLAS BELl, MA, FRCS, RICHARD H Hunt, FRCP, FRCP(EDIN), FRCPC
}

$\mathrm{O}$ NE OF THE MAIN THEMES OF THE WORLD CONGRESS WAS Helicobacter pylori and its role in peptic ulcer disease. This was addressed by a working party chaired by Professor Tytgat (1) and discussed in numerous abstracts. The large number of reports from developing countries confirmed that this is a worldwide problem with geographical variations in prevalence. Of particular interest was a report from Hunan province in the People's Republic of China (2), which found a prevalence of $86 \%$ in asymptomatic young adults being screened for esophageal carcinoma, which has a high incidence in this province.

A direct comparison between two rural populations was also reported (3), with a significantly higher prevalence of $H$ pylori in southern India (91\%) compared to Tennessee, United States (68\%). The mean age of the $H$ pylori-positive patients was lower in the Indian population (37 years compared to 61 years), and this group also had a higher incidence of duodenal ulcer (25\% versus 13\%). However, these results may reflect the different indications for endoscopy in the two countries.

Two longitudinal studies from Scandinavia were reported

McMaster University Medical Centre, Division of Gastroenterology, Hamilton, Ontario

Correspondence and reprints: Dr RH Hunt, McMaster University Medical Centre, Division of Gastroenterology, 1200 Main Street West, Room 4WB, Hamilton, Ontario L8N 325 and had been designed to investigate whether the association between $\mathrm{H}$ pylori infection and ulcer disease is opportunistic or causal. Investigators from Copenhagen (4) followed 74 patients with healed duodenal ulcers for two years, with endoscopic biopsies every three months which were scored according to the load of $\mathrm{H}$ pylori observed. They found no increase in recurrent duodenal ulceration with increasing infection (4). A study from Finland (5) looked at 96 patients with gastric ulcers and found over $80 \%$ to have coexisting $H$ pylori infections. However, only eight of 12 patients continued to have $H$ pylori infection when followed up at five years, and of these, only three had active ulceration. Thus, although $\mathrm{H}$ pylori was again highly associated with gastric ulcer, the ulcerogenic role of the organism has not been confirmed.

If $\mathrm{H}$ pylori infection is in itself ulcerogenic, it does not appear to cause an increase in acid secretion. Wagner et al from Hannover, Germany (6) studied 52 patients with duodenal ulcers or chronic active gastritis and compared them to 11 healthy controls. They measured $24 \mathrm{~h}$ intragastric $\mathrm{pH}$ and assessed $\mathrm{H}$ pylori status by culture, histology and the rapid urease test. They found intragastric acidity to be significantly greater in duodenal ulcer patients than in healthy controls or gastritis patients. However, there was no difference in acid profiles between infected and uninfected subjects within either group. McColl and colleagues (7) from Glasgow measured plasma gastrin concentrations and intra- 
gastric acidity before and at one and seven months after eradication of $\mathrm{H}$ pylori in a group of patients with $\mathrm{H}$ pylorirelated antral gastritis and a history of duodenal ulcer. They found no difference in either day or nighttime intragastric $\mathrm{pH}$ with eradication of $\mathrm{H}$ pylori, but both the median basal gastrin concentration and the integrated gastrin response to a peptide meal fell significantly one month after elimination of $\mathrm{H}$ pylori; this change was maintained at seven months. It is interesting that the observed changes in gastrin were not paralleled by changes in intragastric acidity. This may reflect sampling techniques, in that measurement of $\mathrm{pH}$ alone makes no allowance for volume secreted. It is not yet entirely clear whether acidity alone is the most important factor in ulceration, or whether the volume of gastric secretion - and hence the acid load delivered to the duodenum - is also important.

The action of omeprazole on $H$ pylori remains controversial. Five papers addressed this topic, three of which found that omeprazole treatment was associated with eradication of H pylori (8-10), the other two showing no effect $(11,12)$. All were limited studies with small patient numbers, and there is clearly a need for a larger controlled trial and studies to explore the possible mechanisms of such an effect. Several possibilities exist and include: overgrowth by other enteric organisms in the stomach which might exclude $H$ pylori, alteration of mucus and changes in immune mechanisms, and the possibility that omeprazole might act directly on a $\mathrm{pH}$ regulatory pump in the bacterial wall.

\section{THE ROLE OF PEPSINOGEN}

Of the other components of gastric secretion, pepsin was also the subject of several papers in Sydney. Two studies from Italy looked at serum pepsinogen I concentrations in duodenal ulcer disease. Testino and colleagues (13) measured serum pepsinogen I by radioimmunoassay in 25 duodenal ulcer patients and 40 healthy controls. They also took endoscopic biopsies from the body of the stomach and calculated the chief cell mass, expressed as a 'zymogenous index' (number of cells per $\mathrm{mm}^{2}$ by thickness of the glandular layer). The results showed a significant decrease in zymogenous index in duodenal ulcer patients compared to controls. In contrast, there was a doubling of serum pepsinogen I from $57.7 \mathrm{ng} / \mathrm{mL}$ in controls to $127.8 \mathrm{ng} / \mathrm{mL}$ in duodenal ulcer patients, a highly significant finding. The same authors also measured parietal cell mass and confirmed that this is increased in duodenal ulcer disease, thereby validating their sampling and counting techniques (14). This is further evidence in support of a pathophysiological importance for pepsinogen I in duodenal ulcer disease. Kaneko et al from Japan (15) reported a study of serum pepsinogen over a three year period in duodenal ulcer patients. Two hundred and twenty-five patients were followed without medication by six monthly endoscopy for three years and were compared to a control group of 200 healthy individuals. Their results showed no difference between controls and patients whose ulcers remained healed, but a higher level of both pepsinogen I and II in those patients whose ulcers relapsed during the study period, compared to controls ( 74.4 versus 57.7 and 19.4 versus
$16.5 \mathrm{ng} / \mathrm{mL}$, respectively). The authors also subdivided the study groups into smokers and nonsmokers and found that pepsinogen I levels were higher in the smoking population with ulcers than in nonsmokers with ulcers, but that this was not so for controls. Smoking would therefore appear to magnify the changes seen rather than account for them. Another Japanese study (16) looked at serum pepsinogen profiles in gastric ulcer. Fourteen patients on maintenance therapy for gastric ulcers were studied for six months, during which 29\% developed recurrent gastric ulceration. Pretreatment total pepsinogen levels were significantly higher in those who developed recurrent ulceration than in those who remained in remission (104 versus $65 \mathrm{mg} / \mathrm{L}$ ); this was especially true for pepsinogen I, although the ratio of pepsinogen I/II was not altered. While this may be useful in predicting ulcer relapse, it does underline the importance of proteases in the disease process.

Omeprazole results in an increase in serum pepsinogen to $202 \pm 54 \mathrm{ng} / \mathrm{mL}$ compared to $96 \pm 31 \mathrm{ng} / \mathrm{mL}$ in duodenal ulcer patients before treatment (17). This increase is seen after 15 days and is maintained for the duration of treatment. Furthermore, although pepsinogen levels gradually drop on stopping treatment, they are still significantly elevated two weeks later. The clinical relevance of these observations is not clear, since pepsin concentrations in gastric juice increase slightly on omeprazole treatment, reflecting the dramatic diminution in volume of gastric secretion. Furthermore, the significant rise in intragastric $\mathrm{pH}$ approaches levels at which peptic activity is almost completely inhibited.

\section{THE TROPHIC ACTION OF GASTRIN}

The action of omeprazole on enterochromaffin-like (ECL) cells was reported by a Swedish group (18). Hypergastrinemia was induced in the rat by acid suppression with omeprazole or ranitidine or by infusion of rat gastrin-17. The proliferation rates of ECL and stem cells were determined using a cell labelling index obtained by combining histamine immunocytochemistry and autoradiography scores after $\left[{ }^{3} \mathrm{H}\right]$. thymidine labelling. The results showed that both ECL and stem cells are targets for mitogenic stimulation by gastrin, and that this occurs regardless of whether acid is stimulated or suppressed and regardless of the mechanism of acid inhibi. tion, be it achieved surgically or pharmacologically by a variety of classes and doses of antisecretory drugs. Omeprazole given to antrectomized rats failed to induce changes in either ECL cells or stem cells, indicating that it is not a direct effect of omeprazole per se, but rather the resultant hypergastrinemia, that induces these changes. Hypergastrinemia also increases plasma histamine concentrations in a dose-dependent manner, and in rats, plasma histamine correlates with ECL cell density in the oxyntic mucosa and may be a useful marker for an increase in ECL cell numbers (19).

The mitogenic action of gastrin is further supported by the finding that patients with ulcerative colitis and hyperplastic polyps may have raised serum gastrin levels (20), and that pentagastrin can promote the growth of a human colon cancer cell line (21). Hypergastrinemia induced by omeprazole 
has a trophic action on rat gastric mucosa but not on rat colonic epithelium (22).

One abstract suggested that enprostil, a synthetic prostaglandin $\mathrm{E}_{2}$ derivative, might have a place in the prevention of omeprazole-induced hypergastrinemia. Omeprazole-treated dogs had significantly raised basal serum gastrin levels, and enprostil lowered elevated portal vein gastrin levels from 135 to $78 \mathrm{pg} / \mathrm{mL}$, it also inhibited the response to an infusion of gastrin-releasing peptide (23).

A further interesting observation on the actions of omeprazole and hypergastrinemia concerned the effect on gastric emptying. Patients with food retention have raised serum gastrin levels, and in a trial of 10 patients, omeprazole delayed the mean half emptying time for solids from 50 to 102 mins but had no effect on liquid emptying time (24). However, in this study from Denmark, six of the 10 patients had undergone previous surgery to the cardia, and there was enormous variation in emptying times in the drug group. Similar findings have been noted in rats, but the clinical significance is not yet clear, and this study does not help to clarify the issue.

\section{NSAID-ASSOCIATED GASTRODUODENOPATHY}

Another controversial topic at Sydney was the prevention of nonsteroidal anti-inflammatory drug (NSAID)-associated gastropathy, the subject of a working party report (25). Up to

\section{REFERENCES}

All citations are from Abstracts (AWCG), Abingdon: The Medicine Group (UK) Ltd, or Working Party Reports (WPRWCG), London: Blackwell Scientific Publications from, The World Congress of Gastroenterology, Sydney, Australia, 1990.

1. Tytgat GNJ, Axon ATR, Dixon MF, et al. Helicobacter pylori: Causal agent in peptic ulcer disease? WPRWCG 1990:36-45.

2. Raedsch R, Crespi M, Waldherr R, et al. Prevalence of gastritis and Helicobacter pylori-infection in adolescents in China. AWCG 1990:PP958.

3. Rohrbach M, Farnum J, Thomas E, et al. Prevalence and histology of Helicobacter pylori: A comparison between a US and Indian population. AWCG 1990:PP950.

4. Clausen MR, Franzmann MB, Holst C, et al. Longitudinal study of the influence of Campylobacter pylori on current risk of duodenal ulcer relapse. AWCG 1990:PP934.

5. Laszewicz W, Sipponen P, Siurala M, Gabryelewicz A. Long term follow-up study of gastric ulcer patients with Helicobacter pylori infection. AWCG 1990:PP941.

6. Wagner S, Gebel M, Freise J, et al. Effect of chronic Helicobacter pylori infection on gastric acidity in patients with gastritis and duodenal ulcer. AWCG 1990:PP943.

7. McColl KEL, Fullarton GM, El Nujumi AM, et al. Serum gastrin and gastric acid status one and seven months after eradication of Helicobacter pylori in duodenal ulcer (DU) patients. AWCG 1990:FP609.

8. Catalano F, Mangiameli A, Toscano MA, et al. Helicobacter pylori and non-ulcer dyspepsia: Efficacy of omeprazole treatment. AWCG 1990:PD116.

9. Tessaro P, Di Mario F, Rugge M, et al. Efficacy of omeprazole in eradicating Helicobacter pylori from gastric mucosa. AWCG 1990:PD109.

10. Vigneri S, Termini R, Scialabba A, et al. Efficacy of omeprazole in healing duodenal ulcer and eradicating Helicobacter pylori from gastric mucosa. AWCG 1990:PP928.

11. Alvisi A, D'Ambrosi A, Ruina M, et al. Relation of
$40 \%$ of patients presenting with an upper gastrointestinal bleed are taking NSAIDs, but it is not clear which patients are at greatest risk. Previous peptic ulcer disease was found to be a poor predictor of further problems, but previous NSAID intolerance was highly correlated with subsequent bleeding or perforation. Patients receiving corticosteroids in addition to NSAIDs also constituted a high risk group.

Six papers confirmed that misoprostol was effective in the prevention of NSAID-associated gastropathy (26-31), and furthermore, that its use would be cost effective in patients over 70 years of age (32). Misoprostol was also effective in healing established NSAID-induced damage (including ulceration, hemorrhagic gastritis and gastric erosions) (33), as were cimetidine (34) and ranitidine (35). Two studies suggested that ranitidine was effective in preventing as well as healing gastric erosions and ulceration (36,37). Another study showed no therapeutic benefit from ranitidine or omeprazole in preventing NSAID damage to the gastric mucosa, but that both protected the duodenum (38). Sucralfate was found to be of no benefit in the prevention of gastric injury and of only limited benefit in the duodenum (39). Thus, it appears that while many agents can heal NSAID-induced gastric injury, only misoprostol has been firmly established as effective for prophylaxis, albeit at the expense of some abdominal symptoms and diarrhea in up to $40 \%$ of patients.

Helicobacter pylori to gastroduodenal peptic disease during omeprazole treatment. AWCG 1990:PP944.

12. Pretolani S, Bonvicini F, Careddu N, et al. Effect of short term therapy with omeprazole in patients with resistant ulcers and Helicobacter pylori gastritis. AWCG 1990:PD100.

13. Testino G, Perasso A, Messore M. Serum pepsinogen I (PG I) and chief cell mass in duodenal ulcer. AWCG 1990:S55.

14. Perasso A, Testino G, Messore M. Chief cell mass and parietal cell mass in duodenal ulcer. AWCG 1990:S62.

15. Kaneko E, Ito G, Hanajima K. Natural history of duodenal ulcer and serum pepsinogen. AWCG 1990:PP652.

16. Miki K, Ichinose M, Kimura M, et al. Studies on the recurrence and intractability of gastric ulcer - with special reference to the levels of serum pepsinogen I and pepsinogen II. AWCG 1990:PP650.

17. Costa F, Bortoluzzi F, Pallini P, et al. The effect of oral omeprazole on serum pepsinogen A (PGA) levels. AWCG 1990:PP1009.

18. Ryberg B, Tielemans Y, Axelson J, et al. Gastrin controls ECL-cell and stem cell proliferation rate in the rat stomach. AWCG 1990:PP444.

19. Waldum HL, Lehy T, Brenna E, et al. Effect of the histamine-1 antagonist astemizole alone or with omeprazole on rat gastric mucosa. AWCG 1990:PP445.

20. Farinati F, Della Libera G, Sturniolo GC, et al. Increased gastrin serum levels in patients with ulcerative colitis and hyperplastic colon polyps. AWCG 1990:PD557.

21. D'Agostino L, Pignata S, Daniele B, et al. Modulation of ornithine decarboxylase expression and putrescine uptake by pentagastrin in human colon cancer cells. AWCG 1990:PP1231.

22. Tielemans Y, Håkanson R, Willems G, Oxyntic and colonic mucosal cell proliferation in hypergastrinemic omeprazole treated rats. AWCG 1990:PP421.

23. Nasu T, Misawa T, Chijiiwa Y, et al. The inhibitory effect of enprostil on omeprazole-induced and GRP-stimulated hypergastrinemia. AWCG 1990:PP970. 
24. Pedersen SA, Rasmussen L, Øster-Jorgensen E, et al. A double-blind placebo controlled trial of omeprazole on characteristics of gastric emptying in healthy volunteers. AWCG 1990:PP153.

25. Langman MJS, Brooks P, Hawkey CJ, Silverstein F, Yeomans N. Management of non-steroidal anti-inflammatory drug gastroduodenopathy: Epidemiology, causation and treatment. WPRWCG 1990:11-6.

26. Bolten W. Investigation on the prophylactic effect of misoprostol on NSAID-associated gastropathy. Two double-blind placebo-controlled studies in 179 patients. AWCG 1990:PP456.

27. Elliott SL, Yeomans ND, Buchanan RRC, et al. Long-term ulcer and erosion prophylaxis by misoprostol in arthritis patients. AWCG 1990:FP16.

28. Fabbri R, Zanarini S, Giungi F. Cytoprotection during longterm NSAID therapy. AWCG 1990:PD333.

29. Lambert R, Delmas P, Ethevenaux C, Capron MH. Prevention of NSAID-induced gastric and duodenal lesions with misoprostol: Multicenter, double-blind, placebo-controlled trial. AWCG 1990:FP606.

30. Levi S, Griffin WMG, Fenn GC, et al. Prevention of NSAID-induced gastric and duodenal damage by misoprostol (Cytotec): A randomised, double-blind, placebo-controlled study. AWCG 1990:PP451.

31. Sambandam R, Chandrasekharan AN, Raghuram K. Double blind placebo controlled clinical trial on cytoprotective effect of misoprostol on 100 patients with NSAID therapy. AWCG 1990:PD314.

32. Gross PF. Economic impact of new cytoprotective drug on NSAID-induced ulceration. AWCG 1990:PP449.

33. Nikopoulos A, Settas L, Theoharidis A, et al. The therapeutic role of misoprostol (a synthetic PG I) in patients with rheumatic diseases and gastroduodenal lesions. AWCG 1990:PD294.

34. Mundo F, Nigl I, Sánchez H. Use of cimetidine 800 mg nocte in the treatment of NSAID induced gastritis. AWCG 1990:PP988.

35. Lancaster Smith M, Jaderberg ME, Jackson DA. Ranitidine in the treatment of NSAID associated gastric and duodenal ulcers. AWCG 1990:PP457.

36. Yanagawa A. Prophylactic efficacy of ranitidine against gastroduodenal mucosal damage from non-steroidal antiinflammatory drugs: A randomised placebo-controlled study. AWCG 1990:PP996.

37. Penston JG, Wormsley KG. NSAID-associated gastric ulcers. Long term maintenance treatment with ranitidine. AWCG 1990:PP989.

38. Oddsson E, Gudjonsson H, Thjodleifsson B. Protective effect of omeprazole or ranitidine against naproxen induced damage to the human gastroduodenal mucosa. AWCG 1990:FP22.

39. Gudjonsson H, Oddsson E, Thjodleifsson B. Protective effect of sucralfate against naproxen induced damage to the human gastroduodenal mucosa. AWCG 1990:PP993. 


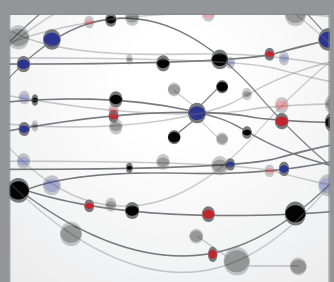

The Scientific World Journal
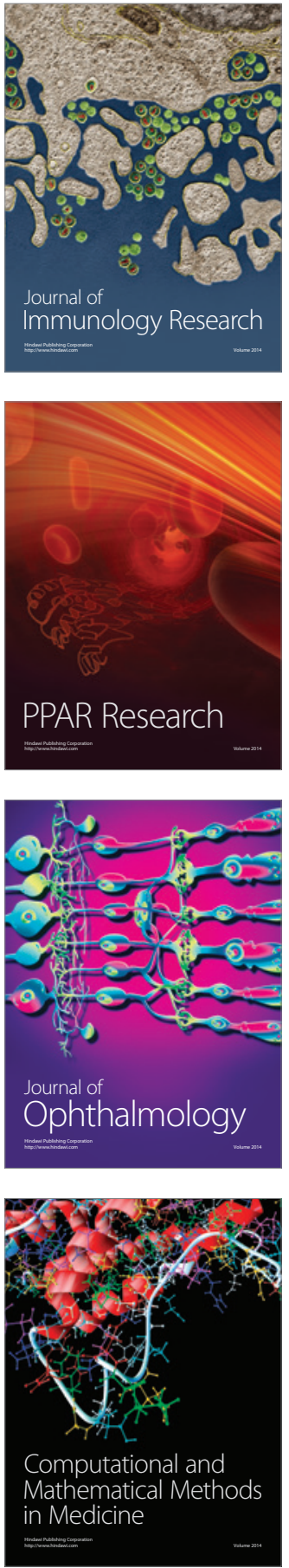

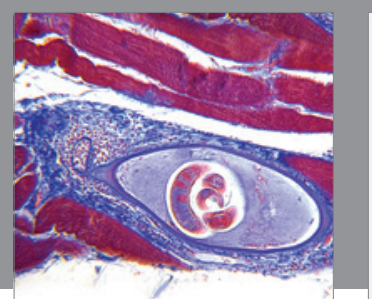

Gastroenterology Research and Practice

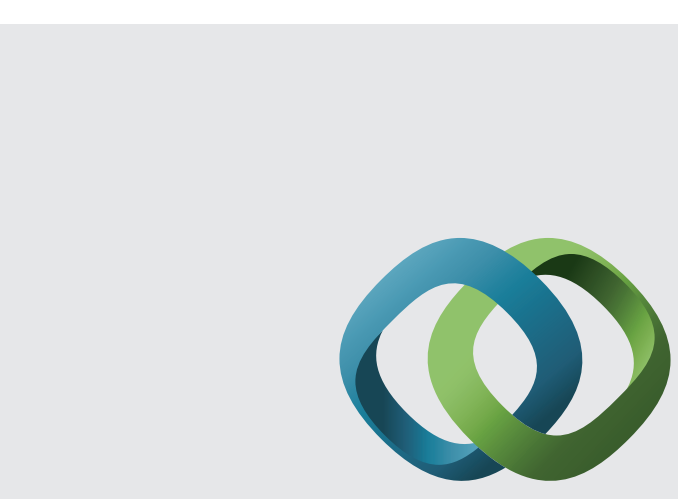

\section{Hindawi}

Submit your manuscripts at

http://www.hindawi.com
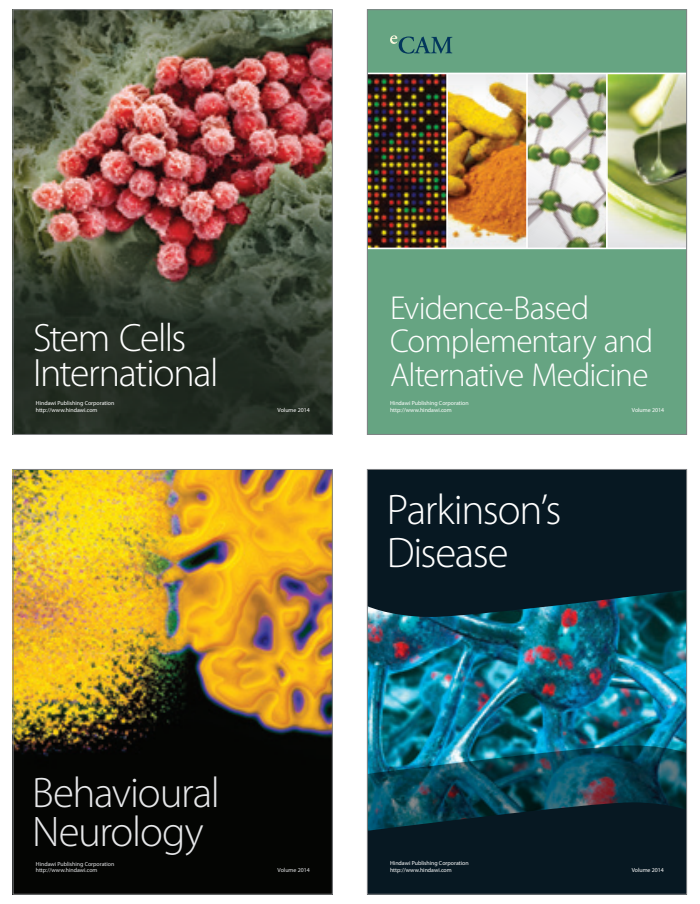
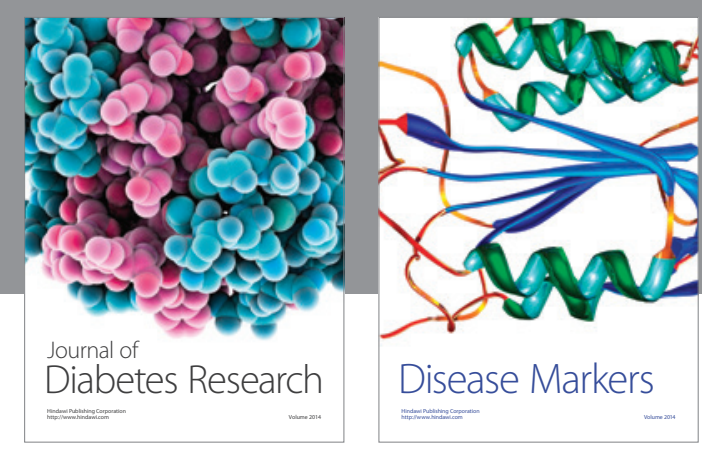

Disease Markers
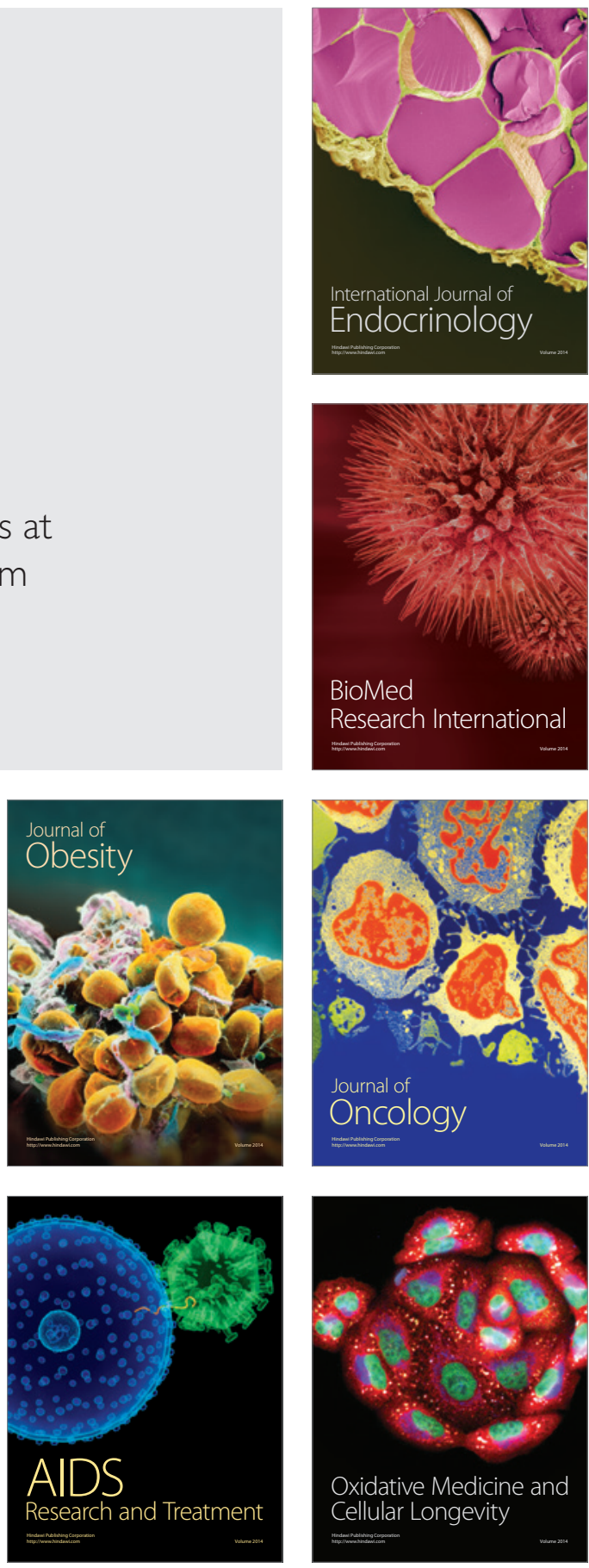